\title{
Becker's Nevus Coexisting with Morphea: A Rare Case Report
}

\author{
Pradeep Kumar $^{\mathrm{a}}$ Sarita Sanke $^{\mathrm{a}}$ Ram Chander $^{\mathrm{a}}$ Anita Nangia ${ }^{\mathrm{b}}$ \\ aDepartment of Dermatology \& STD, Lady Hardinge Medical College and associated Hospital, Delhi, India; \\ bepartment of Pathology, Lady Hardinge Medical College and associated Hospital, Delhi, India
}

\section{Established Facts}

- Becker's nevus (BN) coexists with other cutaneous disorders: intradermal nevi, malignant melanoma, leiomyoma, lymphangioma, and acneiform eruptions.

- These associations are called BN syndrome.

\section{Novel Insights}

- Becker's nevus (BN) coexisting with morphea was not reported by previous literature.

- Morphea can be an interesting incidental occurrence within a large plaque of BN rather than part of BN syndrome.

- Our case probably represents an association between morphea and BN because of a possible explanation: fibroblast overactivity is noted in both the disease, which leads to focal dermal thickening (morphea) within large plaque of $\mathrm{BN}$.

\section{Keywords}

Becker's nevus · Morphea · Dermoscopy

\section{Abstract}

Becker's nevus (BN) is an acquired unilateral hyperpigmented hairy macule, whereas morphea is a chronic connective tissue disease of unknown etiology, characterized by skin thickening with increased quantities of collagen in the indurated lesion, usually involving the upper trunk and proximal extremity. The occurrence of both disease in the same anatomical site and individual was not reported previously. We report this rare case in a 17-year-old, Indian girl and was di- agnosed after clinical histopathology and dermoscopic correlation. Morphea can be an interesting incidental occurrence within a large plaque of $\mathrm{BN}$.

(c) 2020 S. Karger AG, Basel karger@karger.com www.karger.com/sad

(c) 2020 S. Karger AG, Base

Karger ${ }^{\prime}=$

\section{Introduction}

Becker's nevus (BN) is an acquired unilateral hyperpigmented hairy macule, usually involving the upper trunk and proximal extremity [1]. BN was first described by Samuel William Becker in 1949 [2]. BN had 4 clinical variants: melanotic, hypertrichotic, mixed types (most 


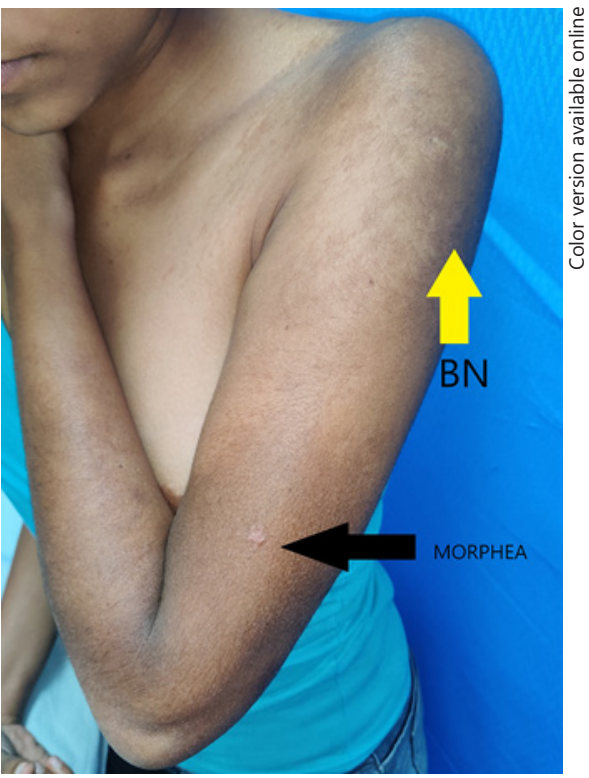

Fig. 1. Clinical images of the left upper limb and shoulder show hypertrichotic and melanotic variant of $\mathrm{BN}$ (yellow arrow) and plaque morphea (black arrow). BN, Becker's nevus.

common), and follicular (new variant) $[3,4]$. BN may be coupled with multiple superficial papules in a few cases. Dermoscopy and skin biopsy help in BN diagnosis. Dermoscopy reveals pigment network, focal hypopigmentation, skin furrow hypopigmentation, hair follicles, perifollicular hypopigmentation, and vessels [5]. Histopathology shows acanthosis, papillomatosis, increased basal layer pigmentation, dermal thickening (hyalinization, fibrosis, collagen swelling, and localized sclerodermoid changes), and melanophages in the papillary dermis [57]. Melanocyte number is normal or slightly increased. Occasionally, hyperplasia of hair follicles, sebaceous glands, and smooth muscle are present.

Morphea is a chronic connective tissue disease of unknown etiology, characterized by skin thickening with increased quantities of collagen in the indurated lesion [8]. Plaque morphea (most common variant) is characterized by well-circumscribed hard and shiny skin limited to the dermis. Dermoscopy shows whitish fibrotic beams (white clouds) with linear branching vessels crossing the beams and the loss of appendages with occasional pigment dots [9-11]. Histopathology examination shows flattened rete ridges, loss of adnexa with minimal inflammation, and collagenization of the dermis.

\section{Case Report}

A 17-year-old girl presented with uniformly hyperpigmented (well- to ill-defined) macule present over the extensor aspect of the proximal third forearm, arm, and left scapular area with tomato splash border for the past 3 years, along with few papules and overlying hypertrichosis. On palpation, ill-defined hyperpigmented indurated plaque of size $2 \times 3 \mathrm{~cm}$ overlies the previously described lesion, just above the elbow (shown in Fig. 1), without musculoskeletal abnormality.

Dermoscopy (AM7013MZTS [4S] Dino-Lite Premier, AnMo corporation, Taiwan, China) of pigmented macule and papule reveals uniformly pigmentary network over the light brown background, with perifollicular hypopigmentation and multiple clusters of reddish-brown globules topped with few radial telangiectasias (shown in Fig. 2a). Dermoscopy of indurated plaque shows yellowish-white globules (corresponding to dermal fibrosis) and black clods (related to pigment incontinence in rete ridges) in the background of uniform pigment network but without telangiectasia (shown in Fig. 3a).

Skin biopsy from hyperpigmented macule reveals orthokeratosis, keratotic plugging, and increased basal pigmentation. Dermis shows perivascular lymphocytic infiltrate and mild pigment incontinence (shown in Fig. 2b). Indurated plaque biopsy shows orthokeratosis, keratotic plugging, mild papillary dermal fibrosis, pigment incontinence, perivascular lymphocytic infiltrate, and pulled up appendages (shown in Fig. 3b). Von Gieson stain shows increased collagenization, focal increase in papillary dermal collagen, and normal elastin. Morphea coexisting with $\mathrm{BN}$ was diagnosed based on the above findings. Subsequently, topical calcineurin inhibitor was given and planned to give methotrexate (for morphea) and Nd-Yag laser for BN.

\section{Discussion}

Clinically and histopathologically, our patient had an acquired isolated morphea and $\mathrm{BN}$ in the same anatomic location. No previous study has described morphea coexisting with $\mathrm{BN}$ in the same individual $[1,3,6-8]$. Our case is a mixed variant (melanotic and hypertrichotic) of $\mathrm{BN}$, whose dermoscopic findings are similar to a study by Ingordo et al. [5]. And dermoscopic findings (yellow-white clouds without linear branching vessels and loss of appendages with multiple pigment dots) of coexisting plaque morphea are in partial agreement with Bhat et al. 

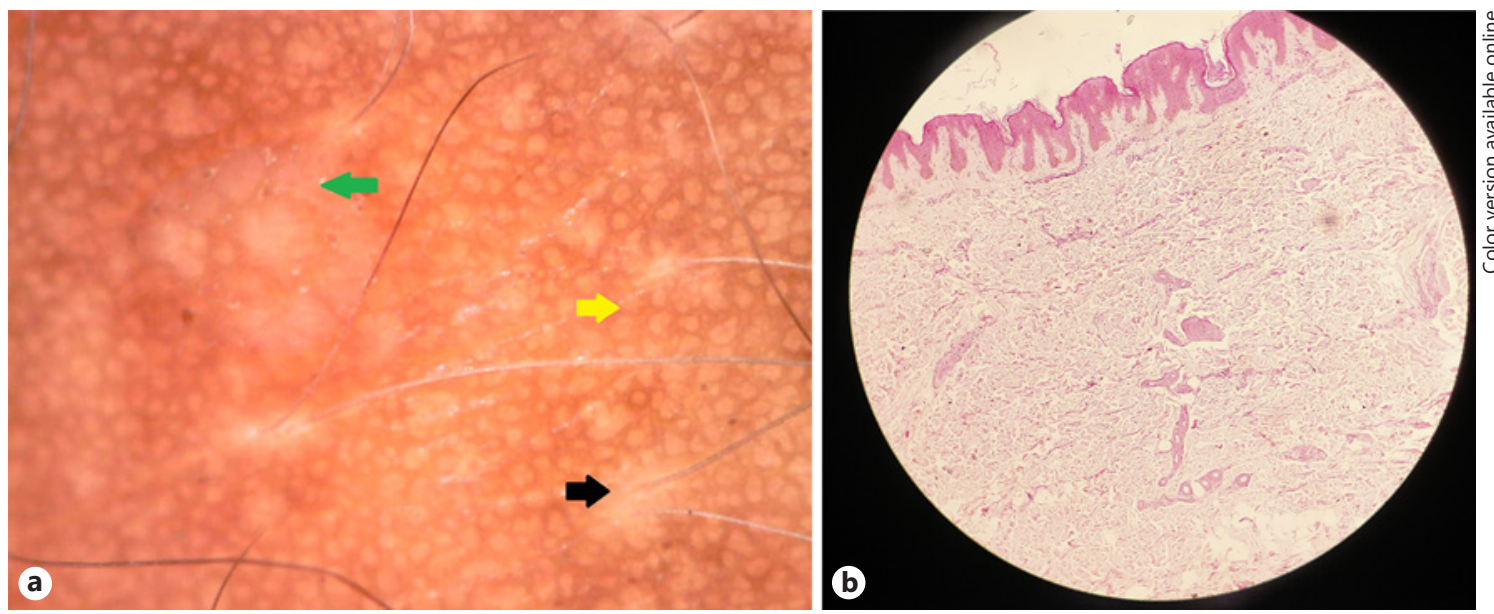

Fig. 2. a Dermoscopy ( $\times 70$ magnification, polarized mode) of pigmented macule and papule reveals uniformly pigmentary network (yellow arrow) over the light brown background, with perifollicular hypopigmentation (black arrow) and multiple clusters of reddish-brown globules topped with few radial telangiectasias (green arrow), respectively. b Skin biopsy from hyperpigmented macule reveals orthokeratosis with keratotic plugging and increased pigmentation in the basal layer in epidermis. Dermis shows perivascular mononuclear inflammatory infiltrate comprising lymphocytes and mild pigment incontinence ( $\mathrm{H} \& \mathrm{E}$ stain, $\times 100$ magnification).
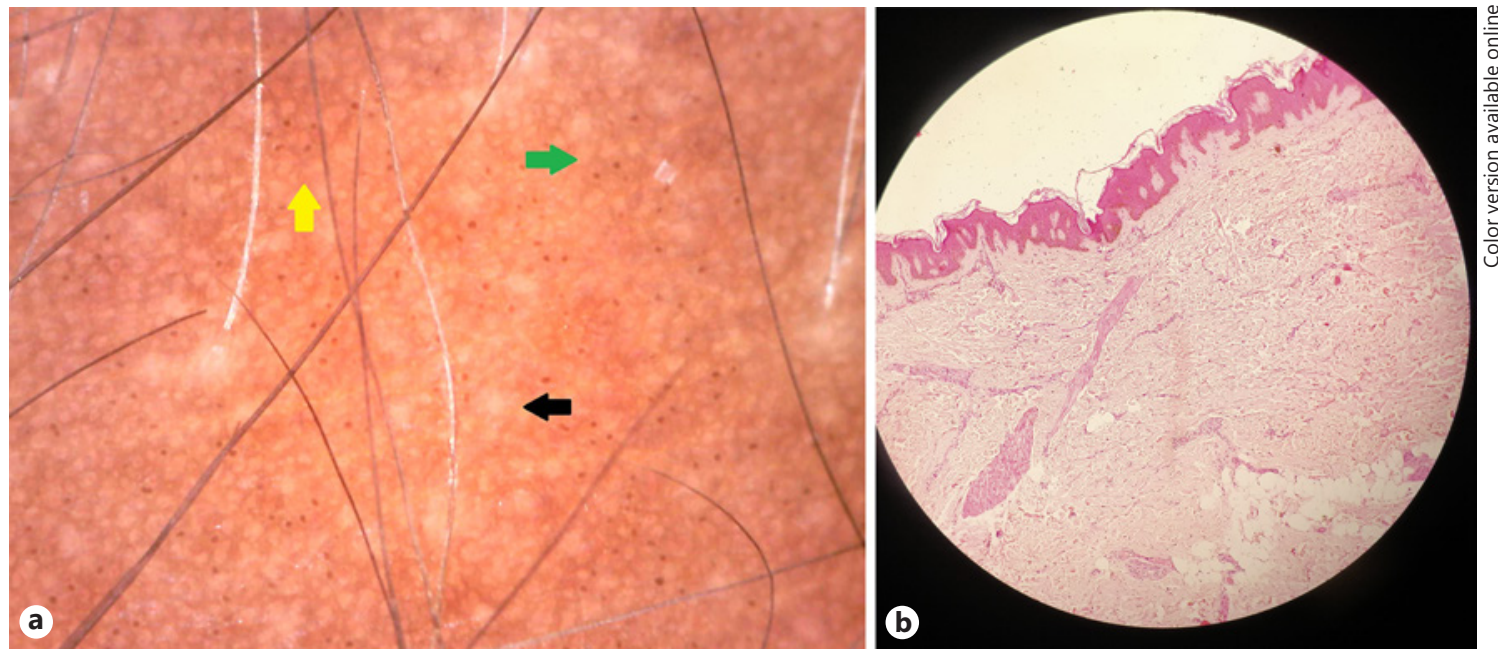

Fig. 3. a Dermoscopy ( $\times 70$ magnification, polarized mode) of indurated plaque shows yellowish-white globules (black arrow) and black clods (green arrow) in the background of uniform pigment network (yellow arrow) but without telangiectasia. b Skin biopsy from the indurated plaque shows orthokeratosis, keratotic plug-

[9], Errichett et al. [10], and Shim et al. [11]. These classical dermoscopic features of morphea may be obscure by $\mathrm{BN}$ coexistence.

However, dermoscopic features are not conclusive in our case but may be used as an adjuvant to other diagnostic modality. BN syndrome (described by Happle, 1997) ging, focal thinning of rete ridges, mild papillary dermal fibrosis, pigment incontinence, and perivascular mononuclear inflammatory infiltrate. And pilosebaceous unit is pulled up with subcutaneous fat lying at the mid dermis (H\&E stain, $\times 100$ magnification).

characterized by $\mathrm{BN}$ associated with cutaneous (intradermal nevi, malignant melanoma, leiomyoma, lymphangioma, and acneiform eruptions), extracutaneous findings (mainly ipsilateral breast hypoplasia), and muscular-skeletal anomalies [12]. Although morphea is not a part of BN syndrome, it more looks like incidental finding. Our case 
probably represents an association between morphea and $\mathrm{BN}$ because of a possible explanation: fibroblast overactivity is noted in both the disease, which leads to focal dermal thickening (morphea) within large plaque of $\mathrm{BN}$ $[6,7]$.

\section{Conclusion}

$\mathrm{BN}$ is a fairly common asymptomatic skin lesion, but induration within these lesions is uncommon. Thus, morphea should be actively looked for, especially in the patients present with indurated $\mathrm{BN}$.

\section{Statement of Ethics}

This study was conducted ethically in accordance with the World Medical Association Declaration of Helsinki, and the subjects (or their parents or guardians) gave their written informed consent to publish photos and details of the case.

\section{Conflict of Interest Statement}

The authors have no conflicts of interest to disclose.

\section{Funding Sources}

The authors did not receive any funding.

\section{Author Contributions}

\begin{tabular}{llccc}
\hline & Contributor 1 & Contributor 2 & Contributor 3 & Contributor 4 \\
\hline Concepts & $\checkmark$ & $\checkmark$ & $\checkmark$ & $\checkmark$ \\
Design & $\checkmark$ & & $\checkmark$ & $\checkmark$ \\
Definition of intellectual content & $\checkmark$ & $\checkmark$ & $\checkmark$ & \\
Literature search & $\checkmark$ & $\checkmark$ & \\
$\begin{array}{l}\text { Clinical studies } \\
\text { Experimental studies }\end{array}$ & $\checkmark$ & & \\
Data acquisition & & & $\checkmark$ & \\
Data analysis & & & $\checkmark$ & \\
Statistical analysis & $\checkmark$ & $\checkmark$ & \\
Manuscript preparation & $\checkmark$ & $\checkmark$ & \\
Manuscript editing & $\checkmark$ & & \\
Manuscript review & $\checkmark$ & & \\
Guarantor & & & \\
\hline
\end{tabular}

\section{References}

1 Alhusayen R, Kanigsberg N, Jackson R. Becker nevus on the lower limb: case report and review of the literature. J Cutan Med Surg. 2008 Jan-Feb;12(1):31-4.

2 Becker SW. Concurrent melanosis and hypertrichosis in distribution of nevus unius lateris. Arch Derm Syphilol. 1949;60(2):155-60.

3 Panizzon R, Brungger H, Vogel A. Becker nevus. A clinicohistologic-electron microscopy study of 39 patients. Hautarzt. 1984;35:57884.

4 Manchanda Y, Khaitan BK, Ramam M, Das S, Al-Mutairi N. Follicular becker's nevus: a new clinical variant. Indian J Dermatol. 2020; 65(2):130-32.
5 Ingordo V, Iannazzone SS, Cusano F, Naldi L. Dermoscopic features of congenital melanocytic nevus and becker nevus in an adult male population: an analysis with a 10 -fold magnification. Dermatology. 2006;212(4):354-60.

6 Glinick SE, Alper JC, Bogaars H, Brown JA. Becker's melanosis: associated abnormalities. J Am Acad Dermatol. 1983;9(4):509-14.

7 Fegeler VF, Schreiner H. Familiares vorkommen von systematisierten pigmentnaevi mit circumscripter sklerodermie imgleichen hautsegment. Hautarzt. 1954;5:253-5.

8 Careta MF, Romiti R. Localized scleroderma: clinical spectrum and therapeutic update. An Bras Dermatol. 2015;90(1):62-73.
9 Bhat YJ, Akhtar S, Hassan I. Dermoscopy of morphea. Indian Dermatol Online J. 2019; 10(1):92-3.

10 Errichetti E, Lallas A, Apalla Z, Di Stefani A, Stinco G. Dermoscopy of morphea and cutaneous lichen sclerosus: clinicopathological correlation study and comparative analysis. Dermatology. 2017;233(6):462-70.

11 Shim WH, Jwa SW, Song M, Kim HS, Ko HC, Kim MB, et al. Diagnostic usefulness of dermatoscopy in differentiating lichen sclerous et atrophicus from morphea. J Am Acad Dermatol. 2012 Apr;66(4):690-1.

12 Happle R, Koopman RJ. Becker nevus syndrome. Am J Med Genet. 1997;68(3):357-61. 